\title{
Deconvolving the effects of lithology, sorting, and chemical weathering using compositional analysis of Irrawaddy River sediments
}

\author{
J. Jotautas Baronas ${ }^{1}$, AleXANDER G. LipP ${ }^{2}$, EMILY \\ I. STEVENSON ${ }^{1}$, MiCHAEL J. BICKLE ${ }^{1}$, Oliver \\ SHORTTLE $^{1}$, EDWARD T. TIPPER ${ }^{1}$
}

${ }^{1}$ Dept. of Earth Sciences, University of Cambridge, UK ${ }^{2}$ Department of Earth Science \& Engineering, Imperial College London, UK

The chemical and isotopic composition of river water and sediments reflects an integrated signal of many physical and biogeochemical processes taking place inside a river basin, allowing us to potentially quantify the fluxes and rates of these processes on a large spatial scale. However, the elemental and isotopic composition of suspended river sediments can also be strongly influenced by spatiotemporal variations in erosiondeposition, heterogeneous lithology, and hydrodynamic sorting of suspended particles during transport, especially in large river basins.

Here, we present elemental and isotopic data of suspended sediment depth profiles from the largely unstudied Irrawaddy River, collected over variable hydrological conditions and across the length of the basin. To constrain sediment sorting in the river channel we use water flow velocity data, coupled to a new Rouse-based hydrodynamic modeling approach. We then show how statistically rigorous compositional data analysis techniques can be used to deconvolve and quantify the competing effects of sediment source mixing, sorting, and chemical weathering in the case of this large, highly complex, river basin. 